\title{
Accuracy of one or two simple questions to identify alcohol-use disorder in primary care:
}

\author{
a meta-analysis
}

\begin{abstract}
Background

There is much interest in ultra-short alcohol screening in primary care that may support brief alcohol interventions. Brief screening consisting of one or two questions might be used alone or in combination with longer tests as recommended by the Primary Care Service Framework.
\end{abstract}

\section{Aim}

To investigate whether a simple one and two question screening might prove an accurate and acceptable screening method in primary care.

\section{Design and setting}

A systematic literature search, critical appraisal and meta-analysis were conducted.

\section{Method}

A comprehensive search identified 61 analyses of single questions to detect alcohol problems including 17 that took place in primary care, using a robust interview standard. Despite focusing alcohol-use disorder in primary care settings, heterogeneity remained high, therefore random effects and bivariate meta-analyses were used.

\section{Results}

After adjustments, diagnostic accuracy of a single-question approach was given by a sensitivity of $54.5 \%(95 \% \mathrm{Cl}=43.0 \%$ to $65.5 \%)$ and a specificity of $87.3 \%(95 \% \mathrm{Cl}=81.5 \%$ to

$91.5 \%$ ) using meta-analytic weighting. Two questions had a sensitivity of $87.2 \% 195 \% \mathrm{Cl}$ $=69.9 \%$ to $97.7 \%$ ) and specificity of $79.8 \%$ (95\% Cl $=75.7 \%$ to $83.6 \%$ ). Looking at each question individually, the most successful single question was a modification of the Single Alcohol Screening Question (SASQ) namely, 'How often do you have six or more drinks on one occasion?'. The optimal approach appears to be two questions followed by the CAGE questionnaire, which achieved an overall accuracy of $90.9 \%$ and required only 3.3 questions per attendee.

\section{Conclusion}

Two brief questions can be used as an initial screen for alcohol problems but only when combined with a second-step screen. A brief alcohol intervention should be considered in those individuals who answer positively on both steps.

\section{Keywords}

alcohol; diagnostic accuracy; diagnostic validity; primary care; sensitivity; specificity.

\section{INTRODUCTION}

Alcohol problems are common in primary care with between $7 \%$ and $30 \%$ of attendees having at-risk drinking or an alcohol-use disorder. ${ }^{1-3}$ In a meta-analysis of five in primary care studies the pooled prevalence of lifetime problem drinking was 19.8\%. ${ }^{4}$ Many authors have therefore suggested that GPs are well positioned to identify and manage alcohol problems. ${ }^{5,6}$ Several effective treatment packages called 'brief alcohol interventions' have been developed and tested. ${ }^{7.8}$ Clearly these interventions require adequate initial identification of alcohol problems, yet only about one-third of such individuals are detected by their GP.9-12 Studies conducted in the US, UK, Australia, and Finland indicate that clinicians frequently do not screen for problem drinking, and fail to address the problem in at least one-third to one-half of cases even when the diagnosis is known. ${ }^{9.13-18} \mathrm{~A}$ recent meta-analysis found that GPs had a clinical detection sensitivity of $42 \%$ but alcohol problems were recorded correctly in the notes only $27.3 \%$ of the time. ${ }^{19}$

In response to these concerns The Institute of Medicine, the National Institute on Alcohol Abuse and Alcoholism (NIAAA), the American Medical Association, and the
American Society of Addiction Medicine have all recommended that clinicians routinely ask patients about alcohol use..$^{20-23}$ In order to screen for problem drinking, the US NIAAA and the US Preventive Services Task Force (USPSTF) recommend population screening; that is, physicians should ask all attendees whether they drink, and assess the specific quantity, frequency, and pattern of consumption, but they did not recommend a specific tool. ${ }^{24}$ In 2004, the USPSTF recommended screening is accompanied by behavioural counselling interventions to reduce alcohol misuse by adults in primary care settings. ${ }^{25}$ The NIAAA also recommends targeted screening (case-finding) in that all patients who drink alcohol should be screened with the four CAGE questions. ${ }^{21}$ In the UK, the Primary Care Service Framework prefers the 10 AUDIT questions; in fact, it recommends an algorithm approach whereby either the Single Alcohol Screening Question (SASQ) (1 item), Fast Alcohol Screening Test (FAST) (4 items), Alcohol-use disorders Identification Test (AUDIT)-C (3 items) or AUDIT-PC (5 items) is applied as an initial first step, followed by the remaining AUDIT questions given to those who initially score positive on the screening test. ${ }^{26}$ Yet choice

\footnotetext{
AJ Mitchell, MD, consultant in psycho-oncology, Leicestershire Partnership NHS Trust and honorary senior lecturer in liaison psychiatry, Department of Cancer and Molecular Medicine, Leicester Royal Infirmary, Leicester. V Bird, BSc, MBPsS, research assistant; M Rizzo, MSc, research assistant, National Collaborating Centre for Mental Health, London. S Hussain, medical student, University of Leicester, Leicester. N Meader, PhD, systematic reviewer, National Collaborating Centre for Mental Health, Royal College of Psychiatrists' Research Unit, London and CORE, University College London, Research Department of Clinical, Educational and Health Psychology, London.
}

\section{Address for correspondence}

Alex Mitchell, Department of Liaison Psychiatry, Brandon Unit, Leicester General Hospital, Leicester, LE5 4PW.

E-mail: Ajm80वle.ac.uk

Submitted: 6 September 2013; Editor's response: 3 December 2013; final acceptance: 25 March 2014.

\section{CBritish Journal of General Practice}

This is the full-length article (published online 30 Jun 2014) of an abridged version published in print. Cite this article as: Br J Gen Pract 2014; DOI: 10.3399/bjgp14X680497. 


\section{How this fits in}

Screening for alcohol misuse in primary care is important because it is common and because brief interventions can be effective. However, the most useful simple screening questions to ask remain to be defined. In a meta-analysis of their use, it appears that both 1-and 2-item screening questions have value, and that they should be followed by a second, more detailed assessment to determine the need for intervention or referral.

of the initial steps is not yet clear, ${ }^{27}$ and no evidence has yet been presented for algorithm approaches.

In reality, many GPs have difficulty applying routine alcohol screening, although most state that they often inquire about drinking behaviours. ${ }^{21,28}$ Indeed observational studies have shown that screening for alcohol problems is

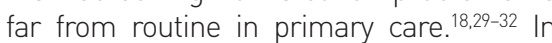
the UK, alcohol screening sometimes occurs at patient registration but is usually opportunistic. ${ }^{33}$ Investigations into alcohol screening practices have consistently found that most physicians ask patients about consumption, but few go beyond an initial inquiry. ${ }^{31,34}$ Most alcohol discussions last less than 1 minute. ${ }^{35}$ D'Amico et al examined primary care physician practices in over 7000 visits; practitioners asked only $29 \%$ of all attendees about their drinking over the course of 1 year, although they asked $44 \%$ of problem drinkers about their drinking. Of those individuals with problem drinking, 49\% received relevant advice. ${ }^{36}$

Lessons from screening studies for depression suggest that ultra-short methods consisting of one or two questions might be valuable in some circumstances. ${ }^{37}$ However such methods often have low positive predictive value. ${ }^{38}$ The aim of this study was to find out whether very simple one and two question screening might prove an accurate and acceptable screening method in primary care using quantitative meta-analysis. It was hypothesised that one question might have good rule-in but poor rule-out performance when used alone.

\section{METHODS}

\section{Inclusion/exclusion criteria}

The principal inclusion criteria were studies that examined the diagnostic accuracy of simple verbal questions to identify those with defined alcohol problems in primary care. No language restrictions were applied.
This study was principally concerned with the accuracy of detecting those individuals with defined alcohol problems, as opposed to an assessment of alcohol intake, therefore to minimise heterogeneity, the criterion standard required lestablished by interview) was the DSM or ICD 'alcoholuse disorder', rather than alcohol dependence. Alcohol-use disorder can be further subdivided into alcohol abuse and alcohol dependence. Studies that did not present sufficient primary data or failed to employ an adequate criterion standard were excluded (such as studies based on self-reported alcohol use). ${ }^{39}$ The initial citations were screened to exclude studies that did not assess 1- or 2-item questions to identify alcohol problems. After this initial sifting process, papers were independently evaluated for eligibility. Disagreements were resolved by discussion.

\section{Search, sources, and appraisal}

A systematic literature search, critical appraisal and meta-analysis were conducted. MEDLINE/PubMed and Embase abstract databases were searched from inception to January 2014 (Appendix 1). In four full text collections (Science Direct, Ingenta Select, Ovid Full text, BlackwellWiley Interscience) the same search terms were used (Appendix 1) but as a full text search and citation search. The abstract database, Web of Knowledge (4.0, ISI) was searched, using the same terms as in Appendix 1 as a text word search, and using key papers in a reverse citation search. Appraisal of each article was conducted by all authors independently using QUADAS.40 This is a standardised quality appraisal form and is recommended by a number of organisations such as the Cochrane Collaboration and the National Institute of Health and Clinical Excellence. No abstracts or non-English articles were found.

\section{Data collection process}

A standardised data extraction form was used, which was developed and piloted on several previous systematic reviews of diagnostic accuracy conducted by the authors. ${ }^{41}$ Data extraction was conducted independently, checked, and differences were resolved by discussion. Variables extracted were: country of study, setting. patient characteristics (such as age and sex), reference standard (including cut-off if relevant), question used to identify alcohol problems, sample size, blindness of the interviewers to the index test, and Youden scores (sensitivity + specificity - 1).42 For the purposes of the meta-analyses sensitivity, 
specificity, and prevalence of alcohol-use disorder las measured by the reference standard) were extracted. In addition, if not provided in the papers, $2 \times 2$ tables (true positives, false positives, true negatives, and false negatives) were calculated from this data for inclusion in the meta-analysis. Secondary outcomes were an area under the curve analysis (see below) for screening and case-finding performance.

\section{Analysis}

Meta-analysis. Random effects metaanalysis were used to synthesise and provide pooled estimates of sensitivity and specificity for the use of a single question or two questions to identify people with alcohol problems. In addition, a bivariate meta-analysis was conducted using the metandi commands in Stata (version 10). This method fits a 2-level model, with independent binomial distributions for the true positives and true negatives conditional on the sensitivity and specificity in each study, and a bivariate normal model for the logit transforms of sensitivity and specificity between studies. ${ }^{43}$ A summary Receiver Operator Characteristic curve (sROC), where each data point represents a separate study, was then constructed using the bivariate model to produce a $95 \%$ confidence ellipse within ROC space. Additionally, a Bayesian curve analysis was undertaken, which plots all post-test probabilities from all pre-test probabilities regardless of prevalence. Heterogeneity was assessed using the $I^{2}$ statistic. ${ }^{44}$ In addition, publication bias was assessed both visually using funnel plots and formally using the Begg-Mazumdar test. ${ }^{45}$

Accuracyand clinical utility. Further analyses were conducted to assess the accuracy and clinical utility of one or two questions to identify people with alcohol problems, both generally lusing any one-question or twoquestion approach) and in comparison with one another. Sensitivity, specificity, positive predictive value (PPV), negative predictive value (NPV), likelihood ratios and clinical utility index were calculated using the online calculator (www.clinicalutility.co.uk). Clinical utility index allows a qualitative measure of clinical accuracy. ${ }^{46}$ Positive clinical utility is a proxy for rule-in accuracy or case-finding. Negative clinical utility is a proxy for ruleout accuracy or screening.

\section{RESULTS}

\section{Study description and methods}

There were 15 tests of individual questions identified in six publications ${ }^{47-52}$ and two tests of two-question approaches, involving 5646 unique individuals. ${ }^{39,50}$ All were diagnostic accuracy studies. The sample size of individual studies ranged from 227 to

Table 1. QUADAS Methodological appraisal of single-question studies

\begin{tabular}{|c|c|c|c|c|c|c|c|c|c|c|c|}
\hline Study ID & $\begin{array}{c}\text { Representative } \\
\text { spectrum? }\end{array}$ & $\begin{array}{c}\text { Reference } \\
\text { standard } \\
\text { acceptable? }\end{array}$ & $\begin{array}{c}\text { Acceptable } \\
\text { delay } \\
\text { between } \\
\text { tests? }\end{array}$ & $\begin{array}{l}\text { Partial } \\
\text { verification } \\
\text { avoided? }\end{array}$ & $\begin{array}{l}\text { Differential } \\
\text { verification } \\
\text { avoided? }\end{array}$ & $\begin{array}{l}\text { Incorporation } \\
\text { avoided? }\end{array}$ & $\begin{array}{c}\text { Ref } \\
\text { standard } \\
\text { blinded? }\end{array}$ & $\begin{array}{c}\text { Index } \\
\text { test } \\
\text { blinded? }\end{array}$ & $\begin{array}{c}\text { Relevant } \\
\text { clinical } \\
\text { information }\end{array}$ & $\begin{array}{l}\text { Uninterpretable } \\
\text { results } \\
\text { reported? }\end{array}$ & $\begin{array}{c}\text { Withdrawals } \\
\text { explained? }\end{array}$ \\
\hline \multicolumn{12}{|c|}{ Single-question studies } \\
\hline $\begin{array}{l}\text { Bradley et al, } \\
2001^{49}\end{array}$ & Unclear & Yes & Yes & Unclear & Yes & No & Yes & Unclear & Yes & No & Yes \\
\hline $\begin{array}{l}\text { Brown et al, } \\
2001^{50}\end{array}$ & Yes & Yes & Yes & Yes & Yes & No & Unclear & Unclear & Yes & No & No \\
\hline $\begin{array}{l}\text { Fleming et al, } \\
1991^{47}\end{array}$ & Yes & Yes & Yes & Yes & Yes & No & Unclear & Unclear & Yes & No & No \\
\hline $\begin{array}{l}\text { Seale et al, } \\
2006^{51}\end{array}$ & Unclear & Yes & Yes & Yes & Yes & Yes & Yes & Unclear & Yes & No & No \\
\hline $\begin{array}{l}\text { Smith et al, } \\
2009^{52}\end{array}$ & Unclear & Yes & Unclear & Yes & Yes & Yes & No & Unclear & Unclear & No & Yes \\
\hline \multicolumn{12}{|c|}{ Two-question studies } \\
\hline $\begin{array}{l}\text { Brown et al, } \\
2001^{50}\end{array}$ & Yes & Yes & Yes & Yes & Yes & No & Unclear & Unclear & Yes & No & No \\
\hline $\begin{array}{l}\text { Vinson et al, } \\
2007^{39}\end{array}$ & Yes & Yes & Yes & Yes & Yes & Yes & Yes & Unclear & Yes & No & No \\
\hline
\end{tabular}


Table 2. Statistical appraisal of single- and two-question studies

\begin{tabular}{|c|c|c|c|c|c|c|c|c|c|}
\hline Author & Phrase of questions & Criterion standard & $\begin{array}{c}\text { Total } \\
\text { sample }\end{array}$ & $\begin{array}{c}\text { All } \\
\text { cases }\end{array}$ & $\begin{array}{l}\text { Non- } \\
\text { cases }\end{array}$ & $\begin{array}{l}\text { Unadjusted } \\
\text { sensitivity }\end{array}$ & $\begin{array}{l}\text { Unadjusted } \\
\text { specificity }\end{array}$ & $\begin{array}{l}\text { Unadjusted } \\
\text { PPV }\end{array}$ & $\begin{array}{l}\text { Unadjusted } \\
\text { NPV }\end{array}$ \\
\hline \multicolumn{10}{|c|}{ Single-question studies } \\
\hline $\begin{array}{l}\text { Seale et al, } \\
2006^{51}\end{array}$ & $\begin{array}{l}\text { SASQ (When was the last time you } \\
\text { had more than } X \text { drinks in one day? }\end{array}$ & $\begin{array}{l}\text { Alcohol-use disorder } \\
\text { (DSM-IV) }\end{array}$ & 625 & 127 & 498 & 0.866 & 0.490 & 0.302 & 0.935 \\
\hline $\begin{array}{l}\text { Fleming } \\
\text { et al, 199147 }\end{array}$ & $\begin{array}{l}\text { Unique - Have you ever had a } \\
\text { drinking problem? }\end{array}$ & $\begin{array}{l}\text { Alcohol-use disorder } \\
\text { (DSM-III) }\end{array}$ & 280 & 82 & 198 & 0.573 & 0.879 & 0.662 & 0.833 \\
\hline \multirow[t]{5}{*}{$\begin{array}{l}\text { Brown et al, } \\
2001^{50}\end{array}$} & $\begin{array}{l}\text { Unique - In the last year, } \\
\text { how many times have you not } \\
\text { remembered things that } \\
\text { happened while you were } \\
\text { drinking or using drugs? }\end{array}$ & $\begin{array}{l}\text { Substance Use Disorder } \\
\text { (CIDI-SAM for DSM-III-R) }\end{array}$ & 1136 & 261 & 875 & 0.483 & 0.925 & 0.656 & 0.857 \\
\hline & $\begin{array}{l}\text { Unique - In the last year, have } \\
\text { you ever drunk or used drugs } \\
\text { more than you meant to? }\end{array}$ & $\begin{array}{l}\text { Substance Use Disorder } \\
\text { (CIDI-SAM for DSM-III-R) }\end{array}$ & 1136 & 261 & 875 & 0.701 & 0.809 & 0.523 & 0.901 \\
\hline & $\begin{array}{l}\text { Unique - Have you felt you wanted } \\
\text { or needed to cut down on your } \\
\text { drinking or drug use in the last year }\end{array}$ & $\begin{array}{l}\text { Substance Use Disorder } \\
\text { (CIDI-SAM for DSM-III-R) }\end{array}$ & 1136 & 261 & 875 & 0.563 & 0.917 & 0.668 & 0.876 \\
\hline & $\begin{array}{l}\text { Unique - In the last year, have you } \\
\text { drunk or used non-prescription } \\
\text { drugs to deal with your feelings, } \\
\text { stress, or frustration? }\end{array}$ & $\begin{array}{l}\text { Substance Use Disorder } \\
\text { (CIDI-SAM for DSM-III-R) }\end{array}$ & 1136 & 261 & 875 & 0.544 & 0.869 & 0.553 & 0.865 \\
\hline & $\begin{array}{l}\text { Unique - As a result of your } \\
\text { drinking or drug use, did } \\
\text { anything happen in the last year } \\
\text { that you wish didn't happen? }\end{array}$ & $\begin{array}{l}\text { Substance Use Disorder } \\
\text { (CIDI-SAM for DSM-III-R) }\end{array}$ & 1136 & 261 & 875 & 0.410 & 0.960 & 0.754 & 0.845 \\
\hline $\begin{array}{l}\text { Bradley } \\
\text { et al, 200149 }\end{array}$ & $\begin{array}{l}\text { SASQ-Modified How often do } \\
\text { you have six or more drinks } \\
\text { on one occasion? }\end{array}$ & $\begin{array}{l}\text { Alcohol-use disorder } \\
\text { (DSM-III-R) or hazardous } \\
\text { drinking (NAAA) }\end{array}$ & 227 & 92 & 135 & 0.772 & 0.830 & 0.755 & 0.842 \\
\hline \multirow[t]{4}{*}{$\begin{array}{l}\text { Volk et al, } \\
1997^{48}\end{array}$} & CAGE: cut down question & $\begin{array}{l}\text { Alcohol-use disorder } \\
\text { (DSM-IV) }\end{array}$ & 1333 & 205 & 1128 & 0.629 & 0.840 & 0.417 & 0.926 \\
\hline & CAGE: annoyed question & $\begin{array}{l}\text { Alcohol-use disorder } \\
\text { (DSM-IV) }\end{array}$ & 1333 & 205 & 1128 & 0.239 & 0.930 & 0.383 & 0.871 \\
\hline & CAGE: guilty question & $\begin{array}{l}\text { Alcohol-use disorder } \\
\text { (DSM-IV) }\end{array}$ & 1333 & 205 & 1128 & 0.371 & 0.900 & 0.402 & 0.887 \\
\hline & CAGE: eye-opener question & $\begin{array}{l}\text { Alcohol-use disorder } \\
\text { (DSM-IV) }\end{array}$ & 1333 & 205 & 1128 & 0.210 & 0.950 & 0.434 & 0.869 \\
\hline $\begin{array}{l}\text { Smith et al } \\
2009^{52}\end{array}$ & $\begin{array}{l}\text { SASQ-Modified How many times } \\
\text { in the past year have you had } \\
\text { X or more drinks in a day? }\end{array}$ & $\begin{array}{l}\text { Alcohol-use disorder } \\
\text { (DSM-IV) }\end{array}$ & 286 & 33 & 253 & 0.879 & 0.672 & 0.259 & 0.977 \\
\hline \multicolumn{10}{|c|}{ Two-question studies } \\
\hline $\begin{array}{l}\text { Brown et al } \\
2001^{50}\end{array}$ & $\begin{array}{l}\text { In the last year, have you ever } \\
\text { drunk or used drugs more than } \\
\text { you meant to? OR Have you felt } \\
\text { you wanted or needed to cut } \\
\text { down on your drinking or drug } \\
\text { use in the last year? }\end{array}$ & $\begin{array}{l}\text { Substance Use Disorder } \\
\text { (CIDI-SAM for DSM-III-R) }\end{array}$ & 1136 & 261 & 875 & 0.793 & 0.779 & 0.518 & 0.927 \\
\hline $\begin{array}{l}\text { Vinson et al } \\
2007^{39}\end{array}$ & $\begin{array}{l}\text { Q1 Recurrent drinking in situations } \\
\text { in which it is physically hazardous, } \\
\text { and Q2 drinking in larger amounts } \\
\text { or over a longer period than } \\
\text { intended }\end{array}$ & $\begin{array}{l}\text { Alcohol-use disorder } \\
\text { (DSM-IV) }\end{array}$ & 623 & 126 & 498 & 0.944 & 0.819 & 0.569 & 0.983 \\
\hline
\end{tabular}

$N P V=$ negative predictive value. $P P V=$ positive predictive value. 
1333 individuals (33-261 with alcohol-use disorders) (Tables 1 and 2). Most studies used a DSM-based definition of alcohol-use disorder, specifically alcohol abuse and no study examined alcohol dependence. One study defined substance abuse according to DSM-III-R..$^{50}$ The pooled prevalence of alcohol-use disorder was $21.0 \%(95 \% \mathrm{Cl}=$ $20.0 \%$ to $22.1 \%$ ).

\section{Diagnostic accuracy of the single-question test}

Across 15 analyses a single-question approach facilitated the identification of 453 out of 800 unique individuals with problem drinking (cases), an uncorrected pooled sensitivity of $56.6 \%$. There was no evidence of publication bias (Begg-Mazumdar: Kendall's Tau-b $=0.21, P=0.29$ ). A single question allowed identification of 2510 or 3087 unique individuals without problem drinking (non-cases), an uncorrected pooled specificity of $81.3 \%$. There was high heterogeneity present $\left(1^{2}=96.3 \%\right)$. On bivariate meta-analysis sensitivity was adjusted to $54.5 \%(95 \% \mathrm{Cl}=43.0 \%$ to $65.5 \%)$ and specificity was $87.3 \%(95 \% \mathrm{Cl}=81.5 \%$ to 91.5\%) (Figure 1). At the stated prevalence, the PPV was $53.3 \% 195 \% \mathrm{Cl}=48.0 \%$ to $58.5 \%)$ and the NPV was $87.8 \%(95 \% \mathrm{Cl}=$ $85.9 \%$ to $89.5 \%$ ). Positive likelihood ratio was $4.29(95 \% \mathrm{Cl}=3.84$ to 4.80$)$ and negative likelihood ratio $0.52(95 \% \mathrm{Cl}=0.48$ to 0.56$)$. The positive clinical utility index score for the single-question test was 0.287 195\% $\mathrm{Cl}=0.286$ to 0.288 ) rated as 'very poor'

ingle-question approach to alcohol-use disorder in primary care l $a=$ unadjusted; $b$ adjusted for unique patients).
The negative clinical utility index score was $0.769(95 \% \mathrm{Cl}=0.769$ to 0.769$)$ rated as 'good'.

Based on the Youden scores of each question, the most accurate single questions appeared to be "How often do you have six or more drinks on one occasion?' from the SASQ-modified version. A negative answer to the 'eye-opener question' from the CAGE and the question As a result of your drinking or drug use, did anything happen in the last year that you wish didn't happen?'; both had excellent rule-out performance with low false negatives.

\section{Diagnostic accuracy of two questions}

There were only two analyses of a twoquestion approach that had an adjusted meta-analysis sensitivity of $87.2 \% \quad$ (95\% $\mathrm{Cl}=69.9 \%$ to $97.7 \%$ ) and specificity was $79.8 \%(95 \% \mathrm{Cl}=75.7 \%$ to $83.6 \%)$. At $21 \%$ prevalence, the PPV value was $53.4 \%$ (95\% $\mathrm{Cl}=49.4 \%$ to $57.6 \%$ ) and the negative predictive value was $95.9 \% 195 \% \mathrm{Cl}=94.6 \%$ to $97.0 \%$ ). Positive likelihood ratio was 4.32 $\mathrm{C} C \mathrm{Cl}=3.86$ to 4.83$)$ and negative likelihood ratio $0.16(95 \% \mathrm{Cl}=0.12$ to 0.21$)$. The positive clinical utility index score for the single-question test was $0.478195 \% \mathrm{Cl}=$ 0.477 to 0.479 ) rated as 'poor'. The negative clinical utility index score was 0.763 (95\% $\mathrm{Cl}=0.762$ to 0.764$)$ rated as 'good'. In terms of specific questions, based on just two comparisons, the optimal combination of questions was recurrent drinking in situations in which it is physically hazardous combined with drinking in larger amounts or over a longer period than intended'.

\section{Algorithm approach versus routine screening}

The merits of an algorithm approach similar to that recommended by the Primary Care Service Framework were examined. An algorithm potentially saves time because only those individuals who screen positive after the first step receive the longer instrument. Using primary care data from two previous meta-analyses a combination of one or two brief questions was compared with either the 4-item CAGE I $n=10$, pooled sensitivity $=71 \%$ specificity $=$ $91 \%)^{53}$ or the 10 -item AUDIT I $n=6$, pooled sensitivity $=61.9 \%$, specificity $91.5 \%) .{ }^{53}$ Then the accuracy of an algorithm approach was examined, namely a single question or two questions followed by either the CAGE or AUDIT (Table 3).

The most accurate single method was the AUDIT followed by the CAGE, then twoquestions and finally a single question. In terms of algorithm approaches the optimal 
Table 3. Algorithm approaches to diagnosis of alcohol problems in primary care in hypothetical 1000 attendees

\begin{tabular}{|c|c|c|c|c|c|c|c|c|}
\hline & $\begin{array}{l}\text { Sensitivity } \\
\text { (95\% Cl) }\end{array}$ & $\begin{array}{l}\text { Specificity } \\
\text { (95\% Cl) }\end{array}$ & $\begin{array}{c}\text { PPV } \\
(95 \% \mathrm{Cl})\end{array}$ & $\begin{array}{c}\text { NPV } \\
(95 \% \mathrm{Cl})\end{array}$ & $\begin{array}{l}\text { Overall } \\
\text { accuracy } \\
(95 \% \mathrm{Cl})\end{array}$ & $\begin{array}{c}\text { Positive clinical } \\
\text { utility index } \\
(95 \% \mathrm{Cl})\end{array}$ & $\begin{array}{c}\text { Negative clinical } \\
\text { utility index } \\
(95 \% \mathrm{Cl})\end{array}$ & $\begin{array}{c}\text { Questions } \\
\text { asked per } \\
100 \text { attendees }\end{array}$ \\
\hline \multicolumn{9}{|c|}{ Combined algorithms } \\
\hline SQ then AUDIT & $\begin{array}{c}0.337 \\
\text { (0.272 to } 0.403 \text { ) }\end{array}$ & $\begin{array}{c}0.989 \\
(0.981 \text { to } 0.996)\end{array}$ & $\begin{array}{c}0.886 \\
\text { (0.810 to } 0.955)\end{array}$ & $\begin{array}{c}0.856 \\
\text { (0.834 to } 879 \text { ) }\end{array}$ & $\begin{array}{c}0.858 \\
(0.837 \text { to } 0.880)\end{array}$ & $\begin{array}{c}0.298 \\
\text { (0.292 to 0.303) } \\
\text { 'v poor' }\end{array}$ & $\begin{array}{c}0.847 \\
\text { (0.847 to 0.847) } \\
\text { excellent' }\end{array}$ & 311 \\
\hline $2 Q Q$ then AUDIT & $\begin{array}{c}0.540 \\
(0.471 \text { to } 0.609)\end{array}$ & $\begin{array}{c}0.983 \\
\text { (0.973 to 0.992) }\end{array}$ & $\begin{array}{c}0.885 \\
\text { (0.829 to } 0.942 \text { ) }\end{array}$ & $\begin{array}{c}0.895 \\
\text { (0.875 to } 0.915 \text { ) }\end{array}$ & $\begin{array}{c}0.894 \\
(0.875 \text { to } 0.913)\end{array}$ & $\begin{array}{c}0.478 \\
(0.474 \text { to } 0.482) \\
\text { poor }\end{array}$ & $\begin{array}{c}0.880 \\
\text { (0.879 to } 0.880) \\
\text { 'excellent' }\end{array}$ & 536 \\
\hline SQ then CAGE & $\begin{array}{c}0.387 \\
(0.319 \text { to } 0.455)\end{array}$ & $\begin{array}{c}0.988 \\
(0.980 \text { to } 0.995)\end{array}$ & $\begin{array}{c}0.886 \\
\text { (0.819 to } 0.952)\end{array}$ & $\begin{array}{c}0.866 \\
\text { (0.844 to } 0.888 \text { ) }\end{array}$ & $\begin{array}{c}0.867 \\
\text { (0.846 to } 0.888 \text { ) }\end{array}$ & $\begin{array}{c}0.343 \\
(0.337 \text { to } 0.348) \\
\text { v poor }\end{array}$ & $\begin{array}{c}0.855 \\
\text { (0.885 to } 0.885) \\
\text { excellent' }\end{array}$ & 184 \\
\hline $2 \mathrm{QQ}$ then $\mathrm{CAGE}$ & $\begin{array}{c}0.620 \\
(0.553 \text { to } 0.687)\end{array}$ & $\begin{array}{c}0.981 \\
(0.972 \text { to } 0.991)\end{array}$ & $\begin{array}{c}0.892 \\
\text { (0.841 to } 0.944 \text { ) }\end{array}$ & $\begin{array}{c}0.912 \\
\text { (0.893 to 0.931) }\end{array}$ & $\begin{array}{c}0.909 \\
(0.891 \text { to } 0.926)\end{array}$ & $\begin{array}{c}0.553 \\
(0.549 \text { to } 0557) \\
\text { 'fair' }\end{array}$ & $\begin{array}{c}0.895 \\
\text { (0.894 to 0.895) } \\
\text { excellent' }\end{array}$ & 334 \\
\hline \multicolumn{9}{|c|}{ Single applications } \\
\hline $\begin{array}{l}\text { CAGE Single } \\
\text { application }\end{array}$ & $\begin{array}{c}0.615 \\
\text { (0.548 to } 0.682 \text { ) }\end{array}$ & $\begin{array}{c}0.915 \\
\text { (0.896 to } 0.934 \text { ) }\end{array}$ & $\begin{array}{c}0.644 \\
\text { (0.576 to } 0.712 \text { ) }\end{array}$ & $\begin{array}{c}0.905 \\
(0.885 \text { to } 0.925)\end{array}$ & $\begin{array}{c}0.855 \\
\text { (0.833 to } 0.876 \text { ) }\end{array}$ & $\begin{array}{c}0.396 \\
(0.392 \text { to } 0.400) \\
\text { poor' }\end{array}$ & $\begin{array}{c}0.828 \\
\text { (0.828 to } 0.828 \text { ) } \\
\text { excellent' }\end{array}$ & 400 \\
\hline $\begin{array}{l}\text { AUDIT Single } \\
\text { application }\end{array}$ & $\begin{array}{c}0.71 \\
\text { (0.647 to } 0.773 \text { ) }\end{array}$ & $\begin{array}{c}0.91 \\
(0.890 \text { to } 0.930)\end{array}$ & $\begin{array}{c}0.664 \\
(0.600 \text { to0.727) }\end{array}$ & $\begin{array}{c}0.926 \\
\text { (0.908 to } 0.944)\end{array}$ & $\begin{array}{c}0.870 \\
\text { (to } 0.849 \text { to } 0.890 \text { ) }\end{array}$ & $\begin{array}{c}0.471 \\
(0.468 \text { to } 0.475) \\
\text { poor' }\end{array}$ & $\begin{array}{c}0.843 \\
\text { (0.842 to } 0.843) \\
\text { excellent' }\end{array}$ & 1000 \\
\hline $\begin{array}{l}\text { SQ Single } \\
\text { application }\end{array}$ & $\begin{array}{c}0.545 \\
(0.476 \text { to } 0.614)\end{array}$ & $\begin{array}{c}0.873 \\
\text { (0.849 to } 0.896 \text { ) }\end{array}$ & $\begin{array}{c}0.517 \\
\text { (0.449 to } 0.584 \text { ) }\end{array}$ & $\begin{array}{c}0.885 \\
\text { (0.862 to } 0.907)\end{array}$ & $\begin{array}{c}0.807 \\
\text { (0.782 to } 0.831 \text { ) }\end{array}$ & $\begin{array}{c}0.282 \\
(0.278 \text { to } 0.285) \\
\text { v p poor }\end{array}$ & $\begin{array}{c}0.772 \\
(0.771 \text { to } 0.772) \\
\text { 'excellent' }\end{array}$ & 100 \\
\hline $\begin{array}{l}\text { 2QQ Single } \\
\text { application }\end{array}$ & $\begin{array}{c}0.87 \\
\text { (0.823 to 0.917) }\end{array}$ & $\begin{array}{c}0.798 \\
\text { (0.770 to } 0.825 \text { ) }\end{array}$ & $\begin{array}{c}0.518 \\
\text { (0.464 to } 0.571 \text { ) }\end{array}$ & $\begin{array}{c}0.961 \\
(0.946 \text { to } 0.976)\end{array}$ & $\begin{array}{c}0.812 \\
\text { (0.787 to } 0.836)\end{array}$ & $\begin{array}{c}0.451 \\
\text { (0.448 to } 0.453) \\
\text { poor' }\end{array}$ & $\begin{array}{c}0.766 \\
\text { (0.766 to } 0.767 \text { ) } \\
\text { excellent' }\end{array}$ & 200 \\
\hline
\end{tabular}

Table shows hierarchical screening algorithms applied to 1000 hypothetical primary care attendees, of whom 200 have alcohol problems. Calculations from

www. clinicalutlity.co.uk. $2 Q Q=$ two questions. $N P V=$ negative predictive value. $P P V=$ positive predictive value. $S Q=$ single question.

combination was $2 \mathrm{QQ}$ then CAGE 10.909 , $95 \% \mathrm{Cl}=0.891$ to 0.926 ) although this was almost identically accurate to the $2 \mathrm{QQ}$ then the AUDIT $(0.894,95 \% \mathrm{Cl}=0.875$ to 0.913 ). These approaches would be more efficient than CAGE or AUDIT alone. For example for the assessment of 100 hypothetical primary care attendees the AUDIT alone would need 1000 questions to be asked ( 10 per subject) but the $2 Q Q$ and AUDIT algorithm would require 536 .

\section{Real-world value}

In the same 100 hypothetical attendee scenario as above, at a prevalence of $21 \%$, a GP using only a single question for alcoholuse disorder would correctly identify 11 cases, missing 10. They would correctly identify 69 non-cases and falsely diagnose 10; the overall accuracy would be $80.4 \%$. Using an algorithm approach at the same prevalence, a GP looking for alcohol-use disorder using an algorithm of a single question followed by the CAGE would correctly identify 8 cases, missing 13. They would correctly identify 78 non-cases and falsely diagnose one; the overall accuracy would be $86.1 \%$.

\section{DISCUSSION}

\section{Summary}

This study is concerned with the methods of detecting those individuals with defined alcohol problems as opposed to an assessment of alcohol intake. In this metaanalysis of 17 tests from seven publications designed to help with the identification of alcohol-use disorder in primary care, a single question had a sensitivity of only $54.5 \%(95 \% \mathrm{Cl}=43.0 \%$ to $65.5 \%)$ and specificity of $87.3 \% 195 \% \mathrm{Cl}=81.5 \%$ to 91.5\%) but two questions had a sensitivity of $87.2 \%(95 \% \mathrm{Cl}=69.9 \%$ to $97.7 \%)$ and a specificity of $79.8 \% 195 \% \mathrm{Cl}=75.7 \%$ to $83.6 \%$ ). Neither approach is recommended alone because their positive clinical utility 


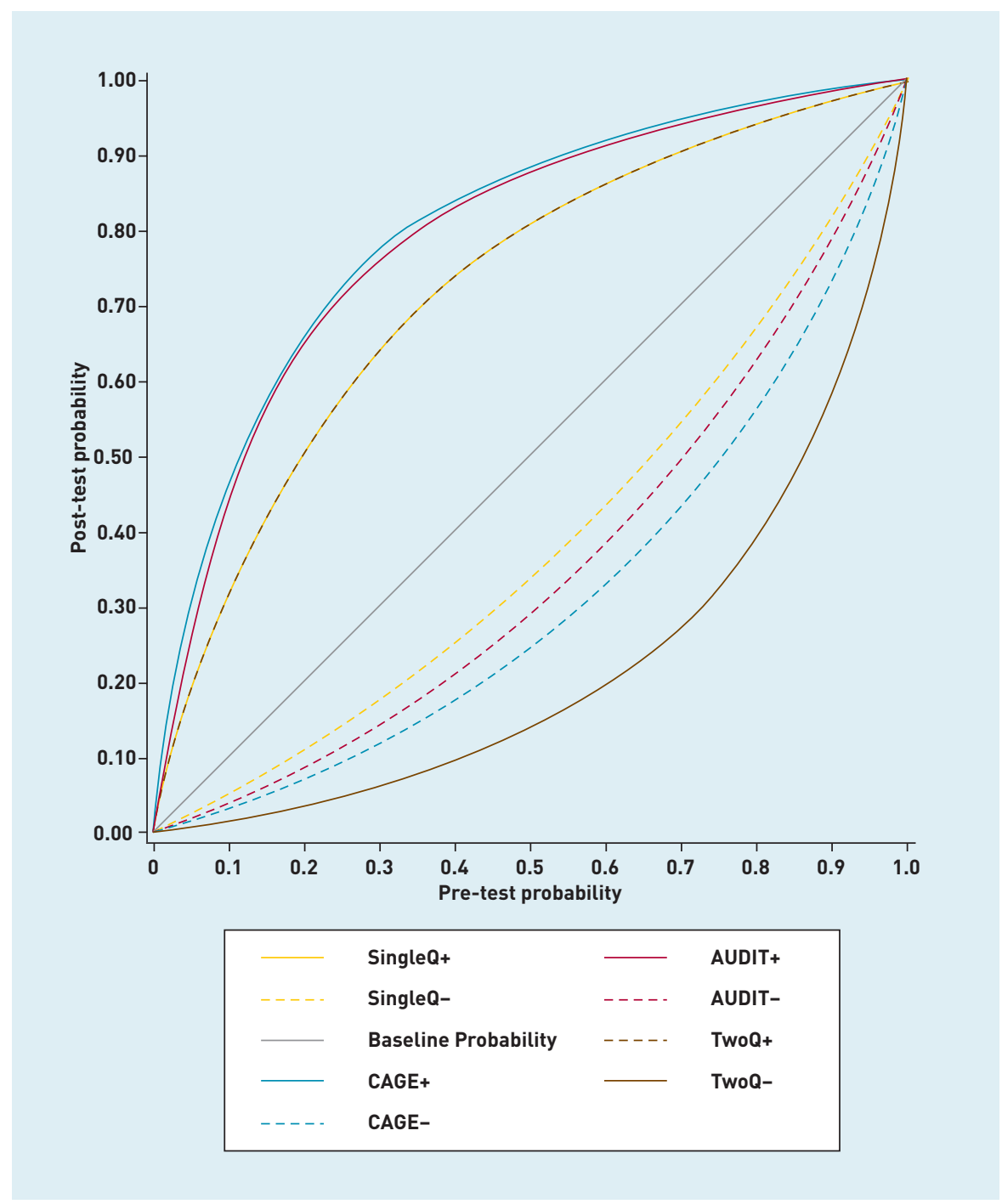

Figure 2. Meta-analytic comparison of single question and two question versus CAGE versus AUDIT in primary care (Conditional probability plot using comparison data from CAGE ${ }^{4}$ and AUDIT ."1 was rated as poor for case-finding. For example, PPV was only $50 \%$ at a prevalence of $21 \%$ (Figure 2). However, when used in algorithmic combination, that is the initial application of one or two questions followed by the longer AUDIT or CAGE only in those who screen positive, then the brief screens are both accurate and efficient.

\section{Strengths and limitations}

This study has several limitations. Despite an extensive search only a small number of studies were found that adhered to a robust interview criterion standard. The study was limited by a lack of data regarding 'at-risk drinking' and 'alcohol dependence'. This could be important as some reports suggest that the CAGE questions perform better in identifying alcohol dependence whereas AUDIT is more sensitive for hazardous and harmful drinkers. ${ }^{54}$ It was also not possible to separate results by sex, although screening differences may exist in clinical practice for males and females. ${ }^{31}$ These issues could be addressed in future research. The study also found considerable statistical heterogeneity which could relate to a wide variety of singlequestion approaches.

\section{Comparison with existing literature}

The merits of algorithmic screening have been previously explored. ${ }^{55}$ The exact approach recommended by the Primary Care Service Framework, namely the SASQ single question "How often do you have six or more drinks on one occasion?' followed by the AUDIT, was reasonably successful. Only two questions followed by the AUDIT and two questions followed by the CAGE were more accurate but at a cost of an additional 2.3 and 0.2 questions per attendee. In clinical practice a GP using only a single question for alcohol-use disorder would be likely to miss 10 cases and falsely diagnose 10 non-cases for every 100 presentations. Using a single question followed by the CAGE the GP would be likely to miss up to 13 cases but with only one false positive. If this rate of missed cases is considered too high, currently the only viable solution is to use a longer questionnaire for all attendees. ${ }^{4,53}$ However the most common questionnaires for alcohol problems (that is the AUDIT, CAGE, and MAST) are usually considered difficult to use in primary care. ${ }^{56-58}$ Clinicians prepared to use a few more than two questions have a choice of the three question AUDIT-C ${ }^{59}$ the 4-item CAGE, ${ }^{4}$ and the 4 -item FAST. ${ }^{60}$ Of these the FAST and CAGE take only 12-15 seconds in experienced hands but their acceptability in primary care is not yet clear. ${ }^{21,32}$ The FAST is of particular interest because item 1 on the FAST is in fact the SASQ question (as above) and the authors recommend an algorithmic approach whereby low and high scorers to question 1 receive no further screening but those with intermediate scores receive three follow-up questions extracted from the AUDIT. However the FAST has yet to be evaluated against an interviewbased criterion standard in primary care, therefore the authors suggest it requires further testing, particularly alongside other approaches. Further, no single laboratory test has been shown to be a substitute for questionnaire-based screening. .11,62 $^{2}$

Routine screening. Experts have recommended routine alcohol screening focusing on new patient registrations, general health checks, and special types of consultation. ${ }^{63-65}$ Mitchell et al previously demonstrated that depression diagnostic 
accuracy can be improved with multiple assessments. ${ }^{66}$ The authors expect the authors group to occur in relation to alcohol assessment because patients are often seen on multiple occasions. A recent meta-analysis found that GPs had a clinical detection sensitivity for alcohol problems of $42 \%$ but a sensitivity of $93.1 \%$ when unassisted..$^{19}$ These figures could be higher in some countries where the recognition of alcohol use is linked to primary care performance incentives. At face value the single-question performance of $54.5 \%$ sensitivity and $87.3 \%$ specificity is not appreciably different from unassisted ability. However, two questions with a sensitivity of $87.2 \%$ and a specificity of $79.8 \%$ does seem to be an improvement. This is similar for ultrashort methods of screening for depression where one question is inadequate but two an improvement over clinician judgement. ${ }^{67}$ Algorithm approaches are better still and can be efficient at the same time. Here the optimal approach appears to be two questions followed by CAGE, which achieved an overall accuracy of $90.9 \%$ and requires only 3.3 questions per attendee.

Acceptability. The clinical value of screening tests depends not only on accuracy but also acceptability. The primary purpose of the single item is as a first-step screen to rule-out those unlikely to have an alcohol problem. The authors suggest it is feasible to require one question to be asked routinely, but it is appropriate to examine acceptability even for a single question, as some questions may not be welcome in unselected primary care attendees. Vinson and colleagues rated patients' comfort with single-item screening. On an ordinal scale in which 1 is very uncomfortable and 5 is 'very comfortable', patients rated their comfort as 4.2 with a single-question approach. ${ }^{18}$ Regarding acceptability for staff, clinicians in Missouri were significantly more likely to use the single question than the CAGE questions $181 \%$ versus $69 \%, P$ $=0.001) \cdot{ }^{18}$ Assuming a prevalence of $20 \%$, this study found that a GP using a single question as the first step, followed by the AUDIT would achieve the same overall accuracy as the AUDIT or CAGE alone but they would require only 121 questions per 100 attendees rather than 1000 with the AUDIT alone and 400 with the CAGE alone (Table 3). Thus an algorithm approach should retain high acceptability, subject to the choice of the first question. In those that screen positive to both steps, consideration should be given to the brief alcohol interventions where required. An updated
Cochrane review identified 24 brief alcohol intervention trials for alcohol problems in general practice..$^{68}$ After $\geq 1$ year, individuals who received a brief intervention drank less alcohol than individuals in the control group laverage difference $38 \mathrm{~g}$ per week, range $23 \mathrm{~g}-54 \mathrm{~g}$ ) although the benefit was not clear for females. A cumulative meta-analysis by date of publication demonstrated that effects have shown significance since 1997..$^{57}$

That said brief alcohol interventions are performed relatively infrequently in primary care. ${ }^{69}$ Only 10\% of GPs reported doing a brief intervention regularly and $50.0 \%$ stated they use this approach occasionally. Furthermore, qualitative work on alcohol screening in the primary care setting in Finland by Aira et al identified that physicians were more comfortable in undertaking a preventive approach for smoking than for alcohol use. ${ }^{70}$ Factors contributing to this difference were difficulties in recognition and determination of the health risk by physicians, lack of effective tools, and lack of positive feedback after interventions. These must also be considered with any attempts to improve implementation of secondary prevention of alcohol misuse. Even clinicians who participate in successful trials do not necessarily continue with screening and intervention after the study closes. ${ }^{56}$ It is important to acknowledge that only one study has examined the implementation of single-item screening in primary care. In 126 current drinkers screening rates for alcohol-use disorder increased from $14.6 \%$ at baseline to $20.0 \%$ after screening implementation and intervention rates rose from $6.3 \%$ to $11.8 \%(P=0.039) .{ }^{71}$

\section{Implications for research and practice}

From the results of this meta-analysis a cautious recommendation from the authors can be given for one or two verbal question as a screening test for alcohol-use disorder in primary care, but only when paired with a longer screening tool to decide who warrants a brief alcohol intervention. Further research is required to clarify the added value of this approach compared with unaided clinical assessment using a randomised screening implementation study.

\section{Competing interests}

The authors have declared no competing interests.

\section{Discuss this article}

Contribute and read comments about this article: www.bjgp.org/letters 


\section{REFERENCES}

1. Buchsbaum DG, Buchanan RG, Lawton MJ, Schnoll SH. Alcohol consumption patterns in a primary care population. Alcohol Alcohol 1991; 26(2): 215-220.

2. Fiellin DA, Reid MC, O'Connor PG. Screening for alcohol problems in primary care: a systematic review. Arch Intern Med 2000; 160(13): 1977-1989.

3. Saitz R. Clinical practice. Unhealthy alcohol use. N Engl J Med 2005, 352: 596-607.

4. Aertgeerts B, Buntinx F, Kester A. The value of the CAGE in screening for alcohol abuse and alcohol dependence in general clinical populations: a diagnostic meta-analysis. J Clin Epidemiol 2004; 57: 30-39.

5. Fleming MF, Barry KL, Manwell LB, et al. Brief physician advice for problem alcohol drinkers: a randomized controlled trial in community-based primary care practices. JAMA 1997; 277: 1039-1045.

6. Friedmann PD, Saitz R, Samet JH. Management of adults recovering from alcohol or other drug problems: relapse prevention in premature care. JAMA 1998: 279: 1227-1231

7. Wallace $P$, Cutler S, Haines A. Randomized controlled trial of general practitioner intervention in patients with excessive alcohol consumption. $\mathrm{Br}$ Med J 1988; 297: 663-668.

8. Bertholet N, Daeppen JB, Wietlisbach V, et al. Reduction of alcohol consumption by brief alcohol intervention in primary care: systematic review and meta-analysis. Arch Intern Med 2005; 165: 986-995.

9. Rydon P, Redman S, Sanson-Fisher RW, Reid AL. Detection of alcoholrelated problems in general practice. J Stud Alcohol 1992, 53: 197-202.

10. Cleary PD, Miller M, Bush T, et al. Prevalence and recognition of alcohol abuse in a primary care population. Am J Med 1988; 85: 466-471.

11. Berner MM, Härter, M, Kriston $L$, et al. Detection and management of alcohol-use disorders in German primary care influenced by non-clinical factors. Alcohol Alcohol 2007; 42 (4): 308-316.

12. Shore J, Spero MM, Buschbaum D. Screening for alcohol abuse among urban Native Americans in a primary care setting. Psych Serv 2002; 53: 757-760.

13. Conigliaro J, Lofgren RP. Hanusa BH. Screening for problem drinking: impact on physician behavior and patient drinking habits. J Gen Intern Med 1998, 13: 251-256.

14. Kaner EF. Heather N, Brodie J, et al. Patient and practitioner characteristics predict brief alcohol intervention in primary care. Br J Gen Pract 2001, 51: 822-827.

15. Aalto M, Pekuri P, Seppa K. Primary health care professionals' activity in intervening in patients' alcohol drinking during a 3-year brief intervention implementation project. Drug Alcohol Depend 2003, 69: 9-14.

16. Richmond RL, Anderson P. Research in general practice for smokers and excessive drinkers in Australia and the UK. III. Dissemination of interventions. Addiction 1994; 89: 49-62.

17. Kaner EF, Lock CA, McAvoy BR, et al. An RCT of three training and support strategies to encourage implementation of screening and brief alcohol intervention by general practitioners. Br J Gen Pract 1999, 49: 699-703.

18. Vinson DC, Elder NC, Werner JJ, et al. Alcohol-related discussions in primary care: a report from ASPN. J Fam Pract 2000; 49: 28-33.

19. Mitchell AJ, Meader N, Bird V, Rizzo M. Clinical recognition and recording of alcohol disorders by clinicians in primary and secondary care: meta-analysis. Br J Psychiatry 2012 201: 93-100. DOI: 10.1192/bjp.bp.110.091199.

20. Institute of Medicine. Broadening the base of treatment for alcohol problems: report of a study by a Committee of the Institute of Medicine, Division of Mental Health and Behavioral Medicine. Washington, DC: National Academy Press, 1990.

21. National Institute on Alcohol Abuse and Alcoholism. The physician's guide to helping patients with alcohol problems. Washington, DC: National Institutes of Health, 1995

22. Council on Scientific Affairs AMA. AMA guidelines for physician involvement in the care of substance abusing patients. Chicago, IL: American Medical Association, 1979.

23. American Society of Addiction Medicine. Public policy statement on screening for addiction in primary care settings. ASAM News 1997; 17: 17-18.

24. US Preventive Services Task Force. Guide to clinical preventive services. 2nd edn. Alexandria, VA: International Medical Publishing, 1998.

25. US Preventive Services Task Force. Screening and behavioral counseling interventions in primary care to reduce alcohol misuse: recommendation statement. Ann Intern Med 2004; 140: 554-556.

26. NHS Primary Care Contracting. Primary Care Service Framework: alcohol services in primary care. http://cdn.pcc-cic.org.uk/sites/default/files/articles/ attachments/primary_care_service_framework_-19may09_clean.doc (accessed 16 Jun 2014).

27. Kaner E, Bland M, Cassidy P, et al. Screening and brief interventions for hazardous and harmful alcohol use in primary care: a cluster randomised controlled trial protocol. BMC Public Health 2009; 9: 287.

28. Herbert C, Bass F. Early at-risk alcohol intake. Definitions and physicians' role in modifying behavior. Can Fam Phys 1997; 43: 639-644.

29. Bradley KA, Curry SJ, Koepsell TD, Larson EB. Primary and secondary prevention of alcohol problems: US internist attitudes and practices. J Gen Intern Med 1995; 10: 67-72.

30. Stange KC, Zyzanski SJ, Jaen CR, et al. Illuminating the 'black box'. A description of 4454 patient visits to 138 family physicians. J Fam Pract 1998 46: 377-389.

31. Stephan Arndt S, Schultz Sk, Turvey C, Petersen A. Screening for Alcoholism in the Primary Care Setting Are We Talking to the Right People? J Fam Pract 2002; 51: 41-46

32. Wenrich MD, Paauw DS, Carline JD, et al. Do primary care physicians screen patients about alcohol intake using the CAGE questions? J Gen Intern Med 1995; 10: 631-634.

33. Farmer R, Greenwood N. General practitioners' management of problem drinkers - attitudes, knowledge and practice. Drugs Educ Prev Policy 2001 8(2): 119-129.

34. Lawner K, Doot M, Gausas J, et al. Implementation of CAGE alcoho screening in a primary care practice. Fam Med 1997; 29: 332-335.

35. Vinson DC, Galliher JM, Reidinger C, et al. Comfortably engaging: which approach to alcohol screening should we use? Ann Fam Med 2004; 2: 398-404

36. D’Amico EJ, Paddock SM, Burnam A, et al. Identification of and guidance for problems drinking by general medical providers. Results from a National Survey. Med Care 2005; 43: 229-236.

37. Mitchell AJ, Coyne JC. Do ultra-short screening instruments accurately detect depression in primary care? A pooled analysis and meta-analysis of 22 studies. Br J Gen Pract 2007; 57(535): 144-151

38. Mitchell AJ. Are one or two simple questions sufficient to detect depression in cancer and palliative care? A Bayesian meta-analysis. Br J Cancer 2008; 98: 1934-1943.

39. Vinson DC, Kruse RL, Seale JP. Simplifying alcohol assessment: two questions to identify alcohol-use disorders. Alcohol Clin Exp Res 2007; 31(8): 1392-1398.

40. Whiting P, Rutjes AW, Reitsma JB, et al. The development of QUADAS: a tool for the quality assessment of studies of diagnostic accuracy included in systematic reviews. BMC Med Res Methodol 2003; 3: 25.

41. Mitchell AJ, Chan M, Bhatti H, et al. Prevalence of depression, anxiety, and adjustment disorder in oncological, haematological, and palliative-care settings: a meta-analysis of 94 interview-based studies. Lancet Oncol 2011; 12: $160-174$.

42. Youden WJ. Index for rating diagnostic tests. Cancer 1950; 3: 32-35

43. Reitsma JB, Glas AS, Rutjes AWS, et al. Bivariate analysis of sensitivity and specificity produces informative summary measures in diagnostic reviews. $J$ Clin Epidemiol 2005; 58: 982-990.

44. Higgins JPT, Thompson SG, Deeks JJ, Altman DG. Measuring inconsistency in meta-analyses. BMJ 2003; 327: 557-560.

45. Begg CB, Mazumdar M. Operating characteristics of a rank correlation test for publication bias. Biometrics 1994; 50: 1088-1101.

46. Mitchell AJ. Sensitivity $\times$ PPV is a recognized test called the clinical utility index (CUI+). Eur J Epidemiol 2011; 26(3): 251-252.

47. Fleming MF, Barry KL. The effectiveness of alcoholism screening in an ambulatory care setting. J Stud Alcohol 1991; 52(1): 33-36.

48. Volk RJ, Cantor SB, Steinbauer JR, Cass AR. Item bias in the CAGE screening test for alcohol-use disorders. J Gen Intern Med 1997; 12: 763-769.

49. Bradley KA, Kivlahan DR, Bush KR, et al. Variations on the CAGE alcohol screening questionnaire: strengths and limitations in VA general medical patients. Alcoholism 2001; 25(10): 1472-1478.

50. Brown RL, Leonard T, Saunders LA, Papasouliotis O. A two-item conjoint screen for alcohol and other drug problems. J Am Board Fam Pract 2001; 14: 95-106. 
51. Seale JP, Boltri JM, Shellenberger S, et al. Primary care validation of a single screening question for drinkers. J Stud Alcohol 2006, 67: 778-784.

52. Smith PC, Schmidt SM, Allensworth-Davies D, Saitz R. Primary Care Validation of a single-question alcohol screening test. J Gen Intern Med 2009; 24(7): 783-788

53. Berner MM, Kriston L, Bentele $M$, et al. The alcohol-use disorders identification test for detecting at-risk drinking: a systematic review and meta-analysis. J Stud Alcohol Drugs 2007; 68(3): 461-473.

54. Fiellin DA, Carrington Reid M, O'Connor PG. Screening for alcohol problems in primary care: a systematic review. Arch Intern Med 2000; 160: 1977-1989.

55. Canagasaby A, Vinson DC. Screening for hazardous or harmful drinking using one or two quantity to frequency questions. Alcohol Alcohol 2005; 40(3): 208-213.

56. Beich A, Gannik D, Malterud K. Screening and brief intervention for excessive alcohol use: qualitative interview study of the experiences of general practitioners. BMJ 2002; 325: 870

57. Beich A, Thorsen T, Rollnick S. Screening in brief intervention trials targeting excessive drinkers in general practice: systematic review and meta-analysis. BMJ 2003; 327: 536-542.

58. Phelps GL, Johnson NP. Bright light in dark places: physician recognition of alcoholism. JSC Med Assoc 1990; 86: 17-18.

59. Kriston L, Holzel L, Welser A-K, et al. Meta-analysis: are 3 questions enough to detect unhealthy alcohol use? Ann Intern Med 2008; 149: 879-888.

60. Hodgson R, Alwyn T, John B, et al. The Fast Alcohol Screening Test. Alcohol Alcohol 2002; 37(1): 61-66.

61. Hoeksema HL, De Bock GH. The value of laboratory tests for the screening and recognition of alcohol abuse in primary care patients. J Fam Pract 1993; 37(3): 268-276.

62. Reynaud M, Schwan R, Loiseaux-Meunier M-N, et al. Patients admitted to emergency services for drunkenness: moderate alcohol users or harmful drinkers? Am J Psychiatry 2001; 158: 96-99.

63. Raistrick D, Heather N, Godfrey C. Review of the effectiveness of treatment for alcohol problems. London: National Treatment Agency for Substance Misuse, 2006.

64. Parker AJR, Marshall EJ, Ball DM. Diagnosis and management of alcoholuse disorders. BMJ 2008; 336: 496-501. DOI:10.1136/bmj.39483.457708.80.

65. Coulton S, Drummond C, James D, et al, for the Stepwice Res Team Opportunistic screening for alcohol-use disorders in primary care: comparative study. BMJ 2006; 332(7540): 511-514A

66. Mitchell AJ, Vaze A, Rao S. Clinical diagnosis of depression in primary care: a meta-analysis. Lancet 2009; 374(9690): 609-619. DOI: 10.1016/S01406736(09)60879-5.

67. Mitchell AJ, Coyne JC. Do ultra-short screening instruments accurately detect depression in primary care? A pooled analysis and meta-analysis of 22 studies. Br J Gen Pract 2007: 57(535): 144-151.

68. Kaner EF, Dickinson HO, Beyer FR, et al. Effectiveness of brief alcohol interventions in primary care populations. Cochrane Database Syst Rev 2007 . 2: CD004148

69. Aalto M, Hyvönen S, Seppä K. Do primary care physicians' own AUDIT scores predict their use of brief alcohol intervention? A cross-sectional survey. Drug Alcohol Depen 2006; 83(2): 169-173.

70. Aira M, Kauhanen J, Larivaara P, Rautio P. Differences in brief interventions on excessive drinking and smoking by primary care physicians: qualitative study. Prev Med 2004; 38(4): 473-478.

71. Seale JP, Guyinn MR, Matthews M, et al. Vital signs screening for alcohol misuse in a rural primary care clinic: A feasibility study. Journal of Rural Health 2008; 24(2): 133-135 


\section{Appendix 1. Search results OVID (Embase and Medline)}

\begin{tabular}{|c|c|c|c|}
\hline$\#$ & Searches & Results & Search Type \\
\hline 1 & $\begin{array}{l}\text { alcohol drinking/ or alcoholtoinduced disorders/ or } \\
\text { disorders, nervous system/ or alcoholtorelated disorders/ }\end{array}$ & 90919 & Advanced \\
\hline 2 & exp Alcohol/ & 97021 & Advanced \\
\hline 3 & $\begin{array}{l}\text { (drink* or alcohol* or substance abuse or substance } \\
\text { misuse).m_titl. }\end{array}$ & 179279 & Advanced \\
\hline 4 & 1 or 2 & 173857 & Advanced \\
\hline 5 & 3 and 4 & 72133 & Advanced \\
\hline 6 & $\begin{array}{l}\text { limit } 5 \text { to ('diagnosis (sensitivity)' or 'diagnosis (specificity)' or } \\
\text { 'diagnosis (optimized)') }\end{array}$ & 14267 & Advanced \\
\hline 7 & $\begin{array}{l}\text { (sensitivity or specificity or ROC or receivertooperator or } \\
\text { accuracy or youden or valid*).mp. [mp=ti, ot, ab, nm, hw, ui, } \\
\text { an, sh, tn, dm, mf] }\end{array}$ & 2249582 & Advanced \\
\hline 8 & 5 and 7 & 5767 & Advanced \\
\hline 9 & 6 or 8 & 16108 & Advanced \\
\hline 10 & (single or question or questions).m_titl. & 198813 & Advanced \\
\hline 11 & 9 and 10 & 96 & Advanced \\
\hline 12 & Primary Health Care/ & 52388 & Advanced \\
\hline 13 & exp Primary Care/ & 92240 & Advanced \\
\hline 14 & $\begin{array}{l}\text { (Primary Care or general practit*].mp. [mp=ti, ot, ab, nm, hw, } \\
\text { ui, an, sh, tn, dm, mf] }\end{array}$ & 144598 & Advanced \\
\hline 15 & 12 or 13 or 14 & 198407 & Advanced \\
\hline 16 & 11 and 15 & 14 & Advanced \\
\hline 17 & remove duplicates from 16 & 10 & Advanced \\
\hline
\end{tabular}

